\title{
A Research on House-purchase Restriction and Internal Migrantsin China: A before-after study
}

\author{
Siyi Zhang* \\ The Chinese University of Hong Kong, Hong Kong, China, 999077 \\ *Corresponding author e-mail: cerizhang@outlook.com
}

Keywords: House-purchase restriction, internal migration, growth rate, DID estimation

\begin{abstract}
For most migrants, residence condition within the immigration areas has been an important factor to make their settlement decision. The internal immigration is a very common phenomenon in China and those migrants' living condition is affected in every aspect of life. This paper aims to explore the influence of the housing policy 'Limited Purchasing Order' on internal migrants in China in recent years and discuss about the major causes and consequences. Although the enactment of the house-purchase restriction has regional differences in cities, the regional pattern and migration distribution overall is quite similar over time. So this paper would ignore the minor differences and collect records of migrants in ten representative immigration cities. The data would be analysed in a theoretical and empirical ways. By applying DID (difference in differences) estimation method, the hypothesis that the limited purchasing order on house negatively affects internal migration willingness, which is represented by growth rate of internal migrants, has been verified.
\end{abstract}

\section{Introduction}

In recent years, real estate industry has developedrapidly in China, especially small property right house with price advantages has encountered a hot sell in urban areas ${ }^{1}$.Meanwhile, the property tax system has not been carried out, the massive real estate speculators push up the housing price. As a result, the soaring housing prices in many provinces of China have attracted the increasing attention. To control this situation, the Chinese government has adopted a series of policies including house-purchase restriction (also called limited purchasing order on house) which is one of the most influential. Announced for the first time in 2010 in Beijing and then progressively implemented in other major cities in China, the house-purchase restriction prohibits both urban resident households and non-resident households from buying houses. Resident households are restricted to purchase at most two houses. For non-resident households, they are limited of one house purchase on condition that they could provide certifications that they have paid tax and social insurance in the city for more than one year. The detailed restriction varies in each area.

As most major cities in China are subject to house-purchase restriction, internal migrants are affected to a large extent. As the household registration system has been released these years, the number of internal migrants in China has been on a constant increase, and it is estimated that China has over 150 million official internal migrants nationwide. It is also suggested that in the 30 years since 1979, the increase of about 340 million in China's urban population was attribute to net migration and urban reclassification ${ }^{2}$. Across China, there are significant differences between provinces, and as a general rule, the further from the east, the greater the rates of poverty, health problems, illiteracy, and the poorer access to electricity and communications. The differences between country and urban areas are becoming larger. Being either unemployed or underemployed, millions of people in the rural districts lack work at home, so they look for migration to the cities as solution. Few rural people are able to be educated beyond high school and those who look for a university education for their children are desperate to move to cities. So most people migrate to improve their lifestyle and are encouraged to move from underdeveloped and inland cities to well- 
developed coastal cities, from rural areas to urban cities (see figure.1), and Chinese government allows them to do so because the migration also narrow regional and rural-urban disparities and reconcile conflicts.

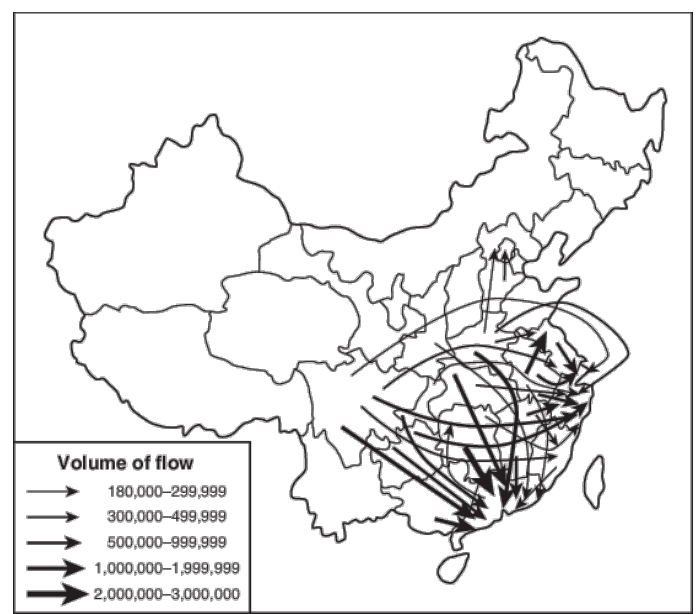

Source: State Council and National Bureau of Statistic.(2007)

Figure 1. The 30 largest interprovincial migration flows. 2000-2005

Internal migratory flow has become the major group in the migrant population in China, reported by "Migrant Population Development Report of China in 2013"3, and they have played an important role in the rapid and unprecedented process of urbanization since mid-1980's. Among the internal migrations in China, whole-household migration has become the main characteristic ${ }^{4}$. Therefore, most migrants might have a strong willingness to get themselves a house and really want to integrate into the urban life ${ }^{4}$. Homeownership could be important to migrants' urban identity and belong ness.

There have been at least three alternative methods for migrating individuals to obtain accommodations in China: acquiring commercial housing through market mechanisms, renting a general department in the city and staying in the urban villages. After the enactment of the limited purchasing order on house, migrants are largely excluded from the mainstream housing distribution system, non-residents such as floating people are not eligible to buy houses in immigrant cities if they do not have qualified proof of tax payment or social insurance payment, or they could at most buy one house, this policy change could have impact on migrants both physically and mentally. For urban migrants who have already settled down, there's no reason that the limited purchasing order would be likely to push them to leave big cities, but for potential migrants, although the regional economic and demographic disparities are key factors which affect or even determine individuals' decisions $^{5}$, it is interesting to examine and discuss how this housing policy influents their settlement willingness in numerical way.

\section{Past Literature}

The limited purchasing order on house property has always been a popular topic among economists since its implementation in 2010. From a review of the literature, there are plenty of researches which have studied about limited purchasing order policy in China, but based on different perspectives. Most of them concerned about the policy's effectiveness on curbing the increasing selling price in housing market and some did research on a series of economic, social and legal problems, which arise from this policy. It is evident and persuasive that the house-purchase restriction really works to some extent as a research reports that the policy has reduced the growth rate of housing prices in Beijing by $7.69^{6}$. It would seem that most research are still work on proving that house-purchase restriction has been useful at reducing housing prices, which is already verified in lots of findings, but almost pay no attention to that in which ways dose the policy affect Chinese citizens' daily life or economic behaviours. On the other hand, there are another group of economists who have done researches on the relationship between homeownership and internal 
migrants in China. For instance, a scholar has examined the complexities and functions of home for internal migrants in contemporary China. ${ }^{7}$ As for migration issue, most literatures choose the number of migrants as the indicator, but do not mention the growth rate of migrants which is also a significant indicator to reflect some facts. Therefore, this paper would like to elaborate the topic and discuss about the issue at a one specific aspect - the relationship between the house-purchase restriction policy and internal migrants in China.

\section{Hypothesis}

There is a clear fact that the primary reason for people to migrant in China is to seek for a better work opportunity and higher wages, which determines that the overall trend for internal migrants from underdeveloped inland cities to well-developed coastal cities and from rural areas to urban areas must be increasing these years. The housing price or the housing policy certainly cannot determine one's decision to migrant or not, it could be an important factor that affects people's consideration, however.So, the first hypothesis is that imposing the house-purchase restriction could influent the growth rate of internal migrants.

The majority of internal migrants is mainly formed by two kinds of people: talent workers and rural migrants workers. The first type of migrants always have completed higher level of education and been enrolled in well-paid jobs, so they do have ability to buy a house and really have a strong willingness to take root in well-developed cities such as Beijing, Shanghai and Shenzhen. However, home-purchase restriction would probably make them feel exclusive so that they would like to consider another city without this policy. For rural migrant workers, most of them just want to meet the basic needs of life and usually rely on renting a department to stay in cities. Although most of rural migrants will not plan to buy houses in urban cities, they are still affected because the limitation of house purchase would drive the demand of housing rent to a higher level unintentionally. With the limited supply of rental housing, the cost of housing rent will rise a lot that most rural migrants even cannot afford and are forced to return to their hometown. On the other hand, being not eligible to own a house in cities might also weaken migrants' overall happiness. Therefore, the constrains imposed on the housing choice together with the temporary residency status of the internal migrants determine their difficult living conditions and unhappiness, it could be assumed that even though the number of internal migrants is still increasing, the speed of growing migrants is lower due to the home-purchase restriction.

\section{Data}

Migrants are mainly distributed in three major destinations - Changjiang Delta, Pearl River Delta, and Beijing/Tianjin areain China, which receive more than $40 \%$ of migrants across the country, while Shanghai and the surrounding areas continue to be highly attractive for migrants ${ }^{5}$. Based on the distribution of internal migration, we choose ten typical immigrant cities as research objects: Beijing, Shanghai, Guangzhou, Shenzhen, Suzhou, Hangzhou, Chengdu, Tianjin, Dongguan and Jiaxing. What needs to be clear is that Dongguan and Jiaxing are two really typical immigrant cities but not experiencing the policy change, for example, in Dongguan in the Pearl River Delta, the average growth rate of migrant labour have reached an extraordinary level of $18 \%$ per year from 2000 to $2004^{8}$, so we choose them as a comparison in this study. Another eight of those objected cities have announced the policy in 2010 or in the early 2011, so it will be assumed that the housepurchase restriction policy has been published in 2010. However, there is no direct and detailed record showing the number of migrants in each areas, so we collected the number of resident population and registered population from year 2008 to year 2011 in all ten cities respectively from National Bureau of Statistics of China. After that, we conduct a simple calculation that subtracts registered population from resident population to obtain the rough floating population. Therefore, the internal immigration growth rate in 2009 and 2011 can be measured respectively. (see figure.2) 


\begin{tabular}{|l|l|l|l|l|l|}
\hline city & year & migration growth rate & after & treatment & interaction \\
\hline Beijing & 2009 & 0.1351 & 0 & 1 & 0 \\
\hline Beijing & 2011 & 0.0532 & 1 & 1 & 1 \\
\hline Shanghai & 2009 & 0.0474 & 0 & 1 & 0 \\
\hline Shanghai & 2011 & 0.0417 & 1 & 1 & 1 \\
\hline Guangzhou & 2009 & 0.1847 & 0 & 1 & 0 \\
\hline Guangzhou & 2011 & -0.0092 & 1 & 1 & 1 \\
\hline Shenzhen & 2009 & 0.0377 & 0 & 1 & 0 \\
\hline Shenzhen & 2011 & -0.0093 & 1 & 1 & 1 \\
\hline Suzhou & 2009 & 0.0734 & 0 & 1 & 0 \\
\hline Suzhou & 2011 & 0.0008 & 1 & 1 & 1 \\
\hline Hangzhou & 2009 & 0.0644 & 0 & 1 & 0 \\
\hline Hangzhou & 2011 & -0.0184 & 1 & 1 & 1 \\
\hline Chengdu & 2009 & 0.0091 & 0 & 1 & 0 \\
\hline Chengdu & 2011 & -0.0467 & 1 & 1 & 1 \\
\hline Tianjin & 2009 & 0.1989 & 0 & 1 & 0 \\
\hline Tianjin & 2011 & 0.139 & 1 & 1 & 1 \\
\hline Dongguan & 2009 & -0.2218 & 0 & 0 & 0 \\
\hline Dongguan & 2011 & 0.0052 & 1 & 0 & 0 \\
\hline Jiaxing & 2009 & 0.049961861 & 0 & 0 & 0 \\
\hline Jiaxing & 2011 & -0.011261261 & 1 & 0 & 0 \\
\hline
\end{tabular}

Figure 2. The city-level data

\section{Methodology}

DID method is typically designed to estimate the effect of a specific intervention or treatment such as an implementation of policy. The idea of using DID is to compare the changes in outcomes over time between a population that is experiencing a policy (the treatment group) and a population that is not (the control group). In this paper, in order to estimate the casual effect of home-purchase restriction on internal migrant growth rate, the difference-in-differences model would make use of longitudinal data from treatment and control groups to obtain an appropriate counterfactual. The advantage for implementing DID estimation is that it focuses on change rather than absolute levels and also allows us to control for a lot of different factors that might otherwise cause end ogeneity. For treatment group, we have eight cities where the policy is carried out : Beijing, Shanghai, Guangzhou, Shenzhen, Suzhou, Hangzhou, Chengdu and Tianjin. For control group, we have two cities which have accepted lots of migrants but have no limitation on housing purchase: Dongguan (in Guangdong province) and Jiaxing (in Zhejiang province).

First, we use the collected date to regress in STATA.DID estimation and standard errors most often derive from using Ordinary Least Squares. And then we typically estimates the following regression using OLS:

$$
\mathrm{Y}=\beta_{0}+\beta_{1} * \mathrm{~T}+\beta_{2} * \mathrm{~S}+\beta_{3}(\mathrm{~T} * \mathrm{~S})+\epsilon
$$

Where dependent variable $\mathrm{Y}$ is the growth rate of internal migrants; $\mathrm{T}$ is a dummy variable for the time period and $\mathrm{T}=1$ when year $=2011$ (after); $\mathrm{S}$ is a dummy variable for group membership and $S=1$ when the city is in treatment group. ( $\left.T^{*} S\right)$ is a dummy for whether the intervention has affected the treatment group in year 2011; $\varepsilon$ is an error term. The estimated impact of the intervention is then the OL Sestimate $\beta_{3}$. 


\section{Regression Results}

From the results obtained by STATA, we could conduct a statistic analysis to test that whether our hypothesis is valid or not. Based on the regression result (figure.1), "Prob $>F=0.0416$ " suggests that this regression model is qualified. The coefficient of "interaction" is - 0.1578384 and $\mathrm{p}$-value is 0.086 , so we could conclude that given others constant, implementing the house-purchase restriction would decrease the growth rate of internal migrants by about $15.78 \%$ at the $90 \%$ significance level. It further shows that our hypothesis is valid that the house-purchase restriction policy has significant impact on the internal migration willingness in a negative way.

\section{Analysis}

\subsection{Causes}

Firstly, the negative impact is mainly caused by the poor living conditions in the immigration areas. The standard of living between the central and western regions did exist for a long time, not to mention the huge difference between urban and rural areas. That's why the migration has continued to be seen as a solution for many people. In every measurable aspect of life, it is expected to be better to live in a well-developed city than in the inland city or in the country. However, moving to where they think a better place makes migrants' life ever harder. In other words, their living cost increase a lot as the home-purchase restriction push up the house-renting prices. According to a survey conducted by a real estate agency, in 2010, the average price of renting houses in Beijing even exceeded 18\% and since then, the annual increase had reached 15\% and 14\% respectively in 2011 and $2012^{9}$. The constantly increasing renting price has become a heavy load for migrants and prevent them from staying in these cities. In addition, as the cost of renting department increase, urban villages are quickly becoming the primary receiving area for most migrants but the housing conditions (both size and qualitative measurement) in urban villages are the worst compared with other alternatives to accommodation. The drop in housing comfort is particularly striking when compared to how most temporary migrants have lived back at home ${ }^{10}$. At the same time, with the increasing rental cost, the corresponding savings that could be spent on entertainment and other stuff that is used to improve the quality of life would be cutting. The reality obviates migrants' high level life expectancy in cities. The expectation-reality discrepancy may then drive internal migrants out of the immigration areas.

Secondly, Migration itself can be a very stress-inducing phenomenon and the limit purchasing order on house has placed much more stress on migrating individuals. Although the primary goal for migrants is to find a better job and make more money than they stay in their hometown, most of them should be aware of paying attention to their emotion or even mental health. Compared with the registered population, migrants have already had fewer channels for expressing their interests and protecting their rights ${ }^{11}$. After the enactment of the house-purchase restriction policy, the restriction could make them feel even more exclusive and unfair compared with the local residents, even though some of them have no plan of buying house all long. The house-purchase restriction has acted like an invisible wall that isolates migrants from where they want to settle down. Furthermore, there are some persuasive researches indicating that people's happiness is correlated with homeownership. According to $\mathrm{Hu}^{12}$, in urban China, homeownership status has a strongly positive impact on both one's housing satisfaction and might even contribute to other possible aspects of life satisfaction. Therefore, for most internal migrants, they are not able to have a sense of belonging and identity in the city, which might affect other aspects of their city life. And another scholars has also admitted that given the overall inadequate housing conditions, temporary migrants nonetheless express less dissatisfaction with their current housing situations than locals ${ }^{10}$. In conclusion, as people start to take into account the emotion of belonging when they decided whether to migrate, the growth rate of internal migrants will decline.

\subsection{Consequences}

The declining growth rate of internal migrants due to the house-purchase restriction leads to 
considerable consequences related to the economic growth and urban development in China.

Firstly, the population flow has brought massive labour force to the urban city. Among these floating population, some people actually do have a university and even higher level education. They are almost enrolled in the financial industry and technology industry with talented skills, so the loss of these highly-educated migrants could hinder the talent introduction and then be completely to the disadvantage of the industry development and economic growth. The central provinces also provide cheap labour to the eastern factories. For rural migrants which account for the majority of the internal migrants, they are demanded by the manufacturing industry and the construction industry for helping to maintain the low-cost advantage, so they are always doing the work that needs the most physical exhaustion but pays a little. In other words, most rural migrant workers are cheap labour. However, without these migrants who have low education, there would be a lack of labour for jobs such as cleaners, waiters and construction workers because most people in urban cities are not willing to do these jobs. The manufacturing industry could not finish the production order without enough factory workers. It is similar in the construction industry and service industry. In the long run, migrants would be the main source of labour for industry in China, so those rural migrants really have played the necessary role in the society. It also shows the fact that internal migrants are growing slower would cause a labour shortage in China's urban sectors and probably slow down the development of society and growth of economic.

Secondly, internal migration is an important factor in the process of urbanization and economic development ${ }^{11}$. The enforcement of the house-purchase restriction policy could place the obstacle on internal migration and contribute to the decline of the urban share of the total population. In addition to decreasing urbanization, low-growing internal migration could have less significant implications for the development of the urban economy since migration also effects the structure of the urban population. The demographic change brought by migration, with regard to gender, age and education level, would not be so obvious that low down the process of urban development ${ }^{11}$.

Despite the clear negative impacts on urban development, the low-growing internal migration does solve some problems. With the fast-growing internal migration, the crime rate rises for that most rural migrants do not receive any law education, and the wealth gap becomes lager and stimulates conflicts. Moreover, the resource and facility would be insufficient because of the growing population in the city. The house-purchase restriction policy has indirectly helped to solve these social problems.

\section{Limitation}

To be honest, there are still some limitations in this paper. The first limitation is that the data may not be absolutely precise. Since there is no direct and accessible official data of the number of migrants in China, we could just calculate the rough number. We have to admit that there may be errors with the measurement. Second, considering that most immigrant cities have implemented housing purchase restrictions, these objects are not so changeable that the results may not be obvious. At the same time, the methodology — Difference in Differences model itself has some limitations because of its many assumptions. For instance, it is appropriate if the interventions are random and conditional on time and group fixed effects, so the effectiveness of DID estimation method often depends on the likely endogenous nature of the intervention ${ }^{13}$. Next, as we mention before, there are few past literature talking about the relationship between the house-purchase restriction policy and the growth rate of internal migrants, so we lack the reference of other researches with the similar topic. Some points in the paper may be a little incomprehensive and lack enough evidence to prove due to the limited time, such as the point about urbanization mentioned in the 'consequences' part. Finally, compared with other researched that discuss the change in the number of migrants, the paper is probably not so impressive and the actual impact in the reality is not so distinct. In the future, this paper should do more further research such as the numerical correlation between urbanization and the growth rate of internal migrants, and conduct a regression to make sure whether the enactment of the house-purchase restriction policy has any impact on the house renting. 


\section{Conclusion}

The key subjective of this paper is to examine and understand the relationship between the house-purchase restriction policy implemented in 2010 and the growth rate of internal migrants in China. Through the data collection and some simple calculations, the growth rate of internal migrants of ten representative cities in 2009 and 2011. This paper uses the DID method to examine the numerical impact that the housing policy has placed on the growth rate of migrants. In the course of analysis, we have demonstrated the causes that account for the negative effect and the consequences of the lower-growing internal migration.

Based on the research, this paper concludes that the house-purchase restriction policy has slowed down the internal migration by around fifteen percent resulting from two aspects: the increasing living cost or poor living condition and the decreasing happiness within the immigration areas. Simultaneously, with the low-growing internal migration, there are fewer labour force for urban sectors and talent workers, and the development of society and economic growth have encountered some problems. However, it also has solved several social issues social issues.

Although the original intention of the Chinese government to impose house-purchase restriction is to curb the soaring housing price, it is not a long-term solution. The policy has ceased in several cities after a few years but the policy makers have imposed more new and strict housing policies again later. And the restriction has never been withdraw in the first-tier cities. These facts could reflect that the Chinese government has many considerations. The house-purchase restriction is reasonable for cutting housing prices, but indeed hurts the migrating individuals. The migrating population is already a vulnerable group in urban cities, these temporary migrants face the limited choices and constraints in their access to urban housing under the strict housing purchasing policy, so the government should care about their current living situation and help to fulfil their basic housing needs.

Finally, the results from the whole analysis of house-purchase restriction may inform the Chinese policy makers to re-evaluate China's internal migration from the perspective of facilitating labour migration and urbanization, and provide migrants the better access to the urban housing system so that they could enjoy similar housing conditions with local residents. At the same time it is necessary for China to work out the improving system for dealing with the migration issue.

\section{Appendix}

\begin{tabular}{|c|c|c|c|c|c|c|}
\hline Source & SS & $d f$ & MS & \multirow{2}{*}{\multicolumn{2}{|c|}{$\begin{array}{l}\text { Number of obs } \\
\mathrm{F}(3,16) \\
\text { Prob > F }\end{array}$}} & \multirow{2}{*}{$\begin{array}{r}20 \\
3.45 \\
0.0416\end{array}$} \\
\hline Model & .061878651 & 3 & .020626217 & & & \\
\hline Residual & .095559469 & 16 & .005972467 & \multicolumn{2}{|c|}{ R-squared } & 0.3930 \\
\hline Total & .15743812 & 19 & .008286217 & \multicolumn{2}{|c|}{$\begin{array}{l}\text { Adj R-squared } \\
\text { Root MSE }\end{array}$} & .07728 \\
\hline g & Coef. & Std. Err. & $\mathrm{t}$ & $P>|t|$ & [95\% Conf. & . Interval] \\
\hline after & .0828884 & .0772817 & 1.07 & 0.299 & -.0809415 & .2467184 \\
\hline treatment & .1797566 & .0610966 & 2.94 & 0.010 & .0502376 & .3092755 \\
\hline interaction & -.1578384 & .0864036 & -1.83 & 0.086 & -.3410059 & .025329 \\
\hline _cons & -.0859191 & .0546464 & -1.57 & 0.135 & -.2017643 & .0299262 \\
\hline
\end{tabular}

Figure 3. Regression result

\section{References}

[1] Guanchen, S. H. E. N., \& Hong, L. I. (2014). A Legal Analysis of Limited Property Right House. Cross-Cultural Communication, 10(3), 55-59. 
[2] Chan, K. W. (2013). China: internal migration. The encyclopedia of global human migration.

[3] Details see the “Migrant Population Development Report of China 2013"issuedby National Health and Family Planning Commission People's Republic of China

[4] Zang, B., Lv, P., \& Warren, C. M. (2015). Housing prices, rural-urban migrants' settlement decisions and their regional differences in China. Habitat International, 50, 149-159.

[5] Zhenzhen, Z. \& Ge, Y. (2016). Internal Migration in China: Changes and Trends. 10.1007/9783-319-24783-0_14.

[6] Du, Z., \& Zhang, L. (2015). Home-purchase restriction, property tax and housing price in China: A counterfactual analysis. Journal of Econometrics, 188(2), 558-568.

[7] Kochan, D. (2016). Home is where I lay down my hat? The complexities and functions of home for internal migrants in contemporary China. Geoforum, 71, 21-32.

[8] Details see the Dongguan Statistical Bureau.

[9] Details see [online] Available:http://finance.sina.com.cn/china/20130413/183815139468.shtml

[10] Wu, W. (2002). Migrant housing in urban China: choices and constraints. Urban Affairs Review, 38(1), 90-119.

[11] Fang, C., \& Dewen, W. (2008). Impacts of internal migration on economic growth and urban development in China. In IOM is committed to the principle that humane and orderly migration benefits migrants and society. As an intergovernmental organization, IOM acts with its partners in the international community to: assist in meeting the operational challenges of migration; advance understanding of migration issues; encourage social and economic development through migration; and uphold the human dignity and well-being of migrants. (p. 245).

[12] Hu, F. Homeownership and Subjective Wellbeing in Urban China: Does Owning a House Make You Happier?. Soc Indic Res 110, 951-971 (2013) doi:10.1007/s11205-011-9967-6

[13] Bertrand, M., Duflo, E., \& Mullainathan, S. (2004). How much should we trust differences-indifferences estimates?. The Quarterly journal of economics, 119(1), 249-275. 